\title{
Perceived Risk of Phoning While Driving: A Case Study from Jordan
}

\section{Authors: Muhannad Muhlsmeik, Ahmed Al-Kaisy, and Khalid Al-Ansari}

NOTICE: this is the author's version of a work that was accepted for publication in Safety Science. Changes resulting from the publishing process, such as peer review, editing, corrections, structural formatting, and other quality control mechanisms may not be reflected in this document. Changes may have been made to this work since it was submitted for publication. A definitive version was subsequently published in Safety Science, VOL\# 78, (October 2015), DOI\# 10.1016/j.ssci.2015.02.011.

Muhlsmeik, Muhannad, Ahmed Al-Kaisy, and Khalid Al-Ansari. "Perceived Risk of Phoning While Driving: A Case Study from Jordan." Safety Science 78 (October 2015): 1-10. doi:10.1016/ j.ssci.2015.02.011. 


\title{
Perceived risk of phoning while driving: A case study from Jordan
}

Revised: $\quad 7$ February 2015

ID: $\quad$ SAFETY-D-13-00531R2

\begin{abstract}
:
The use of mobile phones while driving is banned in most countries since it impairs driving performance and is believed to increase crash risk. The aim of this research is to identify the prevalence of phoning while driving in Jordan and to examine the association between drivers' perception of risk and potential predicting variables. A sample of 423 drivers was surveyed to gather information on their mobile phone use while driving as well as their risk perception. Data collection took place anonymously at diverse locations through a self-report questionnaire. Statistical analysis was performed to highlight the association between risk levels and drivers' demographics and exposure characteristics. An alarming rate of $93.1 \%$ of drivers, mostly young male college students, engaged in this unsafe behavior despite being aware of the associated risk and legislative laws. Findings suggested gender, employment status, age, education level, driving experience, and daily traveled distance were associated with mobile phone use while driving. Recommendations to enhance traffic safety were proposed and further research directions were highlighted.
\end{abstract}

Keywords: Driving, mobile phone, crash, survey, traffic safety. 


\section{Introduction}

Drivers regularly engage in a wide variety of multi-tasking activities when they are behind the wheel. Such activities may include talking to passengers, eating, drinking, lighting a cigarette, listening to music or phoning. Engaging in these multi-tasking activities while the vehicle is in motion often diverts the driver's attention from driving. Such activities may contribute to crashes with estimates as high as one-half of crashes being related to these multi-tasking activities (Bellinger et al. 2009; Young et al. 2013; Irwin et al. 2015).

Recently, there has been a large increase in public and scientific interest on the impacts that communication technology may have on traffic safety. This interest has been spurred on by the growing ownership and increasing usage rates of mobile phones. These phones are a new addition to the array of possible devices that appear inside a vehicle. Unlike radios, global positioning systems, multimedia devices, mobile phones probably represent the first wave of truly driver-interactive devices with several related physical and mental activities. Such activities distract drivers' attention since they are more cognitively engaging and are performed over longer time periods (Caird et al. 2014; Klauer et al. 2014). These activities may include talking, answering, reaching for, preparing to dial, retrieving, picking up a dropped device, as well as reading/writing text messages.

Researchers have raised safety concerns when a mobile phone is used in motion or even in the absence of interaction with the device. Experimental studies, conducted using driving simulators or instrumented vehicles, showed mobile phone use while driving resulted in poor speed maintenance, decreased vehicle control, failure to maintain an appropriate headway position, increased mental workload, increased reaction time, poor lateral control of vehicle, and difficulty in identifying events and traffic signals (McCartt et al. 2006; Harrison 2011). In addition, and contrary to common beliefs among the public, research across a wide range of driving behaviors showed hands-free systems seemed not to offer essential safety advantage over hand-held devices (Backer-Grondahl and Sagberg 2011).

Some studies estimated the percentage of crashes resulting from mobile phone use in motion. In a study of crashes among American students, Seo and Torabi (2004) highlighted that at least $21 \%$ of reported crashes and near-crashes involved at least one of the drivers talking on a mobile phone. And about 1\% of drivers in Australia crashed while using their mobile phones (McEvoy et al. 2006). In Denmark, a crash rate of $0.5 \%$ was found for predominantly male heavy vehicle drivers as a result of mobile phone use and $6 \%$ of drivers experienced dangerous situations on account of their mobile phone use in the previous year (Troglauer et al. 2006). Nurullah et al. (2013) stated 7.6\% of drivers in Alberta, Canada, were involved in a crash due to talking on a mobile phone during the 12-month period used in the study.

Mobile phones are widely used in vehicles and with service providers producing more interactive features, the total time and exposure to risk are estimated to increase. Available research on the effects of drivers' use of mobile phones in motion provided convincing evidence that mobile phone use in vehicles creates a safety risk. However, none of the studies agreed on the magnitude and definition of risk, its linkage to real road crashes, and on the best approaches for lowering it (McCartt et al. 2006; Beck et al. 2007; Klauer et al. 2014).

Some studies suggested that talking on a mobile phone while driving may increase the risk of being involved in a crash by between two and nine folds (Redelmeier and Tibshirani 1997; Laberge-Nadeau et al. 2003; Wilson et al. 2003; Backer-Grondahl and Sagberg 2011); while others (Klauer et al. 2006; Olson et al. 2009; Dingus et al. 2011) found that talking itself is 
not associated with an increase in risk, however, engaging in other mobile phone-related subtasks (reaching for, answering, dialing, texting, and internet use) may further increase crash risk (Simons-Morton et al. 2014; Fitch et al. 2015; Irwin et al. 2015). Thus, the crash risk associated with the use of mobile phone while driving should not be considered a simple dichotomous task (yes/no). Considerable attention should be given to individual mobile phone related subtask since each is associated with a varying level of risk (Hickman and Hanowski 2012).

Despite the lack of hard data, some studies linked and identified several mobile phone activities as being related to crash involvement when a mobile phone was used by a driver. For example, Wilson et al. (2003) found drivers talking on mobile phones had higher counts of prior traffic violations, missed twice as many traffic signals, and were more likely to swerve into the next lane, tailgate, and ran red lights. Seo and Torabi (2004) found an association of in-vehicle mobile phone use with crashes. They showed the more frequently drivers used a mobile phone while driving, the more crashes or near-crashes they experienced. Crundall et al. (2005) indicated the interference deriving from the conversation itself was a potential risk indicating higher talk duration increased the risk. Wogalter and Mayhorn (2005) suggested that activities, such as dialing, answering, and talking on a mobile phone increased the driver's cognitive load and diverted some attention away from the driving task which could contribute to increased frequency of vehicular crashes. Beck et al. (2007) indicated mobile phone users were more likely to engage in several risky activities that place them at greater crash risk than non-mobile-using drivers. Green (2007) suggested dialing numbers on a mobile phone required drivers to look at the device before each button sequence was pushed. As the number of digits to be dialed increased, the number of glances to the device also increased. Glance frequency and glance duration to dial a number affected drivers' capability to scan for hazards and respond to them adequately. Walsh et al. (2008) linked higher perceived risk to the frequency of mobile phone activities (answering and making calls) when used in motion. Schlehofer et al. (2010) showed those drivers talked more often on the mobile phone while driving had poorer real-world driving records resulting in higher crash risk.

A comprehensive literature review about mobile phone use while driving, its trends among drivers, and the safety consequences of such usage, is documented by Collet et al. (2010a, b).

\section{Study motive}

The remarkable growth of mobile telecommunications in Jordan has been extremely rapid and phenomenal. The Telecommunications Regulatory Commission (TRC 2014) reported the number of wireless telephone subscribers grew from a few hundred to about 11 million between 1996 and 2014 with an ownership of 1.7 devices per capita. In line with this exponential increase, there is also a general perception of the widespread use of mobile phones in motion among drivers with great concern on road safety. The exact figure of the number of drivers using their mobile phones while driving is still unknown but it is believed such usage is rapidly increasing every year, despite the ban which was passed on hand-held devices in October 2001.

In many countries including Jordan, there is an ongoing debate among lawmakers and the public on the best approaches of lowering possible mobile phone related crashes (McCartt et al. 2006). Some favor strict regulation and enforcement including a full ban on mobile phone use in motion (McCartt et al. 2010); others require turning the device off or setting it to silent 
mode while driving due to the disturbance of phone rings (Holland and Rathod 2013); others argue more driver education, focused not only on mobile phone use, but on all other distracting activities, is sufficient to allay safety concerns (Wilson et al. 2003; Stavrinos et al. 2011).

In Jordan, there is a need for data to better understand the risk associated with mobile phone use while driving as well as the factors which influence this risk. Unfortunately, until now, data are not available to safety professionals and policymakers. Police crash reports, filled out at the time of crash, do not indicate whether the driver was phoning at the time of crash. Therefore, with the current crash reporting system, it is difficult to assess the association, if any, between crash involvement risk and mobile phone use while driving.

Despite the negative impacts reported in the literature of phoning while driving on safety and driving performance, little is known about how drivers perceive the risk of engagement with a mobile phone while driving, and the association between risk perception and the activities related to mobile phone use. The current study, therefore, aims at investigating how the risk, associated with mobile phone use while driving, is perceived by drivers in Jordan, a Middle Eastern country, where this habit has become commonplace and part of the culture during the last decade. This study, which is a continuation of the work conducted by Ismeik and AlKaisy (2010), attempts to answer the following questions:

1) What is the prevalence of driver's engagement in mobile phone use while driving, and the characteristics of such drivers?

2) What is the driver's risk perception associated with mobile phone use while driving?

3) What is the association between risk levels and driver's characteristics?

4) What are the factors that contribute to risk perception?

This investigation is expected to reveal patterns and trends that are important in developing national traffic safety policies, and other interventions targeted at curbing the impacts of this phenomenon on traffic safety.

\section{Methodology}

\subsection{Participants}

A self-report questionnaire survey was chosen as the mechanism for obtaining data related to extent of use and perceived risk of phoning while driving among drivers. A total of 23 survey sites were chosen randomly and were spread widely across the country. Sites included malls, restaurants, hotels, universities, libraries, cinemas, courts, hospitals, cafes, gas stations, and public parks. Due to the diversity of the selected locations, it is believed the participants in this study were broadly representative of the driving population. To be eligible to complete the survey, participants had to 1) hold a valid driving license; 2) be at least 18 years of age; 3 ) own a mobile phone; and 4) be the primary driver of an automobile. Of the 1175 drivers approached, 647 declined participation and 528 agreed to participate with a response rate of $44.9 \%$. The most common reason for non-participation was lack of time. Sample size was largely dictated by the trade-off between the time needed to conducting the survey and the resources available. As illustrated in Figure 1, 423 questionnaires were deemed appropriate for use in the study as incomplete questionnaires (105) were screened out. 


\subsection{Procedure}

Prospective participants were approached by a research member and were requested to participate in the study. The survey moderator introduced himself to potential participants and informed them that the purpose of this study was to enhance the driving safety related to mobile phone use while driving and the results would be used only for educational purposes. Participants were told this study needed their assistance in providing information about their mobile phone use. Participants were assured of anonymity and confidentiality. Participation was voluntary with no incentives provided. Participants had to read and agree with the survey eligibility terms before starting the survey. If eligibility requirements were met and the person agreed to participate, then the questionnaire was passed along with instructions requesting the participant to honestly complete the survey on-site. The average length of time per survey was 5 minutes. Strict confidentiality and anonymity procedures were maintained with no identifying data collected.

\subsection{Survey instruments and measures}

As illustrated in Table 1, the questionnaire consisted of 14 questions and was divided into four sections. Section 1, 4 questions gathered descriptive demographic information, such as gender, employment status, driver age, and education level. Section 2, 4 questions gathered descriptive exposure information, such as driving experience, license type, daily traveled distance, and time of driving. Section 3, 5 questions measured mobile phone activities by the driver and were rated by an ordinal increasing scale with zero being the smallest value. Two questions assessed the frequency of using a mobile phone and of looking at the device prior to answering calls. Two questions determined the number of incoming and outgoing calls. Then, a question measured the conversation duration over the mobile phone. Section 4 measured participant's perception of risk percentage as related to mobile phone use while driving.

\subsection{Statistical analysis}

The 423 questionnaire responses were carefully entered and coded into a spreadsheet database for analysis. Descriptive analyses were conducted due to the majority of the questions $\left(\mathrm{Q}_{1}-\mathrm{Q}_{8}\right)$ in this survey being qualitative (categorical) in nature. Pearson Chi-square $\left(\chi^{2}\right)$ test was used to explore possible statistical association among the categorical variables. Logistic regression analyses were performed to determine the relative degree of association between various variables with odds ratios calculated at a 95\% confidence interval. Multivariate linear regression was used to analyze the relationship between perceived risk (PR) and possible mobile phone activities ( $\left.\mathrm{Q}_{9}-\mathrm{Q}_{13}\right)$. In the process of building the model, stepwise reduction procedure was used to eliminate the variables whose effect was deemed insignificant. F-test and student's t-test were used to validate the model and variable selection. A significant level of 5\% was considered appropriate for all statistical analyses. Further details about Pearson Chi-square test and multivariate linear regression could be found in McClave and Sincich (2006), with successful applications in various civil engineering areas given by Ashteyat et al. (2012, 2014).

\section{Results and discussion}

\subsection{Mobile phone use with demographics and exposure characteristics}

Table 2 presents the rates of mobile phone use cross-tabulated with the demographics and exposure characteristics of participants. The very high prevalence rates of mobile phone use while driving observed in this study suggest this behavior was a widely accepted practice among drivers. A total of 394 (93.1\%) of drivers reported using their mobile phones on the 
road regardless of the legislation ban. This finding is higher than other mobile phone use surveys conducted in Finland (Poysti et al. 2005), France (Brusque and Alauzet 2008), Spain (Gras et al. 2007), New Zealand (Hallett et al. 2011), Australia (McEvoy et al. 2006; Young and Lenne 2010), Canada (Nurullah et al. 2013) and US (Seo and Torabi 2004; Beck et al. 2007; Braitman and McCartt 2010), all of which found that up to $86 \%$ of drivers reported using their mobile phones while driving.

Participants were 357 (84.4\%) males and 66 (15.6\%) females, and gender differences prevailed. The odds ratio was 12.835 [3.307-49.804] indicating males were more likely than females to use their mobile phones while driving. This was similar to findings reported by Ivers et al. (2009), Hallett et al. (2011), and Nurullah et al. (2013). In terms of employment, $125(29.6 \%)$ participants were working in the public sector, $106(25.0 \%)$ were working in the private sector, and $192(45.4 \%)$ were students. Results indicated that public sector and private sector employed drivers were less likely to use their mobile phones while driving compared to students with odds ratios of 0.840 [0.153-4.602] and 0.126 [0.026-0.604], respectively. Drivers' age ranged from 18 to 69 years with the majority (57.2\%) being in the range of 21-30 years old. Average age for male participants was 29.8 years with a range between 18 and 69 years, and for females was 30.5 years with a range between 18 and 67 years. Younger age groups reported the highest percentages of mobile phone use in motion as compared with 41+ year age group. The 21-30 years old group reported mobile phoning 6.063 [1.076-34.174] times more often than the oldest group (41+ years old). The other groups (18-20 year old) and (31-40 year old) were less prone to phone while driving compared with the (21-30 year old) group with odds ratios of 2.966 [0.287-30.623] and 1.544 [0.271-8.776], respectively. Age had a negative relationship with mobile phone use as younger participants were more likely than older ones to use mobile phones while driving. This was consistent to similar research where younger drivers were more likely to use their mobile phones in vehicles (Walsh et al. 2008; Harrison 2011; Nurullah et al. 2013). In terms of education level, about $38.6 \%$ of participants were high school graduates or had a Diploma degree (2 years post-high school education). The BS degree holders (4-year college graduates) stand out among the rest of other education levels. This group was the heaviest users of mobile phones with an odds ratio of 4.557 [0.665-31.210] compared to high school graduates, Diploma and MS/PhD degree holders.

Driving experience of drivers ranged from 1 to 25 years. Over three quarters of participants had a driving experience between 6 and 12+ years. The average years of driving experience of participants was 11.2 years $(\mathrm{SD}=6.4)$. The average years of driving experience for males was 11.4 years $(\mathrm{SD}=6.2)$ and 9.7 years $(\mathrm{SD}=7.2)$ for females. Driving experience had a positive relationship with mobile phone use as less experienced drivers were less likely than more experienced ones to use mobile phones while driving. The odds ratios of $(<2$ years $),(2-5$ years), and (6-11 years) groups were 0.142 [0.026-0.775], 0.040 [0.006-0.253], and 0.783 [0.174-3.519], respectively as compared with the (12+) year group. About $13.9 \%$ of participants held a professional driver license and the remaining $86.1 \%$ held a private driver license. Participants' license type did not result in statistically significant differences. Daily traveling distance ranged between $10 \mathrm{~km}$ and $45 \mathrm{~km}$ with an average value of $31 \mathrm{~km}$ per day. Traveled distance results suggested the groups of (10-20) km and (21-40) km travelers were less frequent users compared with those who traveled more than $41+\mathrm{km}$ per day with odds ratios of 0.973 [0.222-4.273] and 0.135 [0.024-0.766], respectively. This indicated drivers who travel long distances were more frequent users of mobile phones. About two thirds of participants were driving during the peak hours $(7 \mathrm{am}-5 \mathrm{pm})$. Driving time did not result in statistically significant differences among the participants. 
Overall, gender, employment status, age, education level, driving experience, and daily traveled distance were all found to be significantly associated with mobile phone use while driving, as summarized in Table 2 .

\subsection{Perceived risk levels with demographics and exposure characteristics}

In order to identify any patterns or relationships between demographics and exposure characteristics, and driver's perceived risk of being involved in a crash, as a result of using the mobile phone while driving, the reported perceived risk was classified into three levels. Low perceived risk when the value was between 0 and 33 percent, moderate perceived risk when the value was between 34 and 66 percent, and high perceived risk for values between 67 and 100 percent. This classification enabled the tabulation of drivers' perceived risk with various demographics and exposure variables as illustrated in Table 3 and Figures 2-10.

The distribution of perceived risk levels among drivers is shown in Figure 2. The risk perception ranged between 20 and $97 \%$, with an average value of $63 \%(\mathrm{SD}=17)$. The data illustrated that $48 \%$ of participants perceived using a mobile phone while driving as highly risky. While another $46 \%$ of participants regarded this behavior as moderately risky. Only $6 \%$ of participants considered this behavior to be of low risk. A primary finding of this study indicated that the majority of participants (94\%) were fully aware of the risk associated with mobile phone use while driving, and were more likely to think such a practice would result in a crash. This finding is in agreement with Nurullah et al. (2013) study in which they reported $71.2 \%$ of participants stated "strongly" agree and another $23.3 \%$ "somewhat" agree that mobile phone use was likely to result in a crash (sum 94.5\%).

Drivers' ratings of the perceived risk suggest that most drivers (94\%) were aware of the risk associated with mobile phone use while driving. However, this did not directly limit their mobile phone use as the number of drivers who used their mobile phones was high $(93.1 \%)$, and despite the banning law imposed in October 2001. This finding is consistent with findings reported elsewhere in the literature (Beck et al. 2007; Gras et al. 2007; Braitman and McCartt 2010; Hafetz et al. 2010; Young and Lenne 2010; Hallett et al. 2011). This raises the question as why drivers use their mobile phones in motion when they are aware of the banning and of the associated risk. Although the answer to this question is not within the focus of this article, the literature cites several explanations to this unsafe practice. For instance, studies by Walsh et al. (2008), and Nemme and White (2010) suggested social approval from friends and family members resulted in mobile phone use while driving. Nelson et al. (2009) indicated the perceived practical and social benefits outweigh the dangers associated with mobile phone use while driving. Hafetz et al. (2010) suggested the social expectation to return calls immediately is another likely factor which influences such usage. Schlehofer et al. (2010) listed three related beliefs that appear particularly promising in explaining mobile phone use while driving: overestimating one's ability to compensate for driving distractions, having a general propensity toward illusions of control, and use of a controlling cognitive style. And Zhao et al. (2013) linked this risky behavior to the driver's personality traits (e.g., attitude and behavior) and susceptibility to risk taking.

As shown in Figure 3, examining the perceived risk level by gender reveals that male drivers generally perceive more risk of phoning while driving compared with female drivers. The high perceived risk level involved $54.9 \%$ of male drivers versus $13.6 \%$ of female drivers. On the other hand, low and moderate perceived risk levels involved a higher percentage of female drivers than male drivers. As for driver employment, students and public sector workers 
expressed higher perceived risk values compared with drivers who work in the private sector, as presented in Figure 4. Specifically, the high perceived risk level involved $53.6 \%$ of the students, $58.4 \%$ of the public sector workers, versus only $27.4 \%$ of the private sector workers. Figure 5 illustrates the distribution of perceived risk level versus drivers' age group. The high perceived risk level involved $58.3 \%$ of the drivers in the age group $21-30$ years, $43.1 \%$ of drivers in the age group $31-40$ years, $33.3 \%$ of the drivers who were 41 or older in age, and only $13.9 \%$ of the drivers who were 20 or younger in age. This classification showed, with the exception of younger drivers of limited driving experience (20 years or younger), older drivers perceived less risk of phoning while driving compared with younger drivers. Drivers with Diploma degree exhibited highest levels of perceived risk followed by those with a bachelor's degree, high school certificate, and $\mathrm{MS} / \mathrm{PhD}$ graduate degrees, respectively, as shown in Figure 6.

In regards to driving exposure, Figure 7 shows drivers with higher driving experience generally exhibited higher level of perceived risk than those with lower driving experience. This is somewhat expected as drivers with limited driving experience may have inadequate appreciation of the cognitive demands of various driving tasks, and the potential impairment to cognitive abilities which may result from distraction. The type of driver license did not show a clear association with the driver's perceived risk level as presented in Figure 8. Figure 9 illustrates that drivers who travel longer distances in the course of their daily activities were more concerned about the risk associated with phoning while driving. Specifically, $65.2 \%$ of the drivers who travel more than 41 kilometers per day perceived high level of risk versus only $36.7 \%$ and $28.4 \%$ of the drivers who travel $10-20$ and $21-40$ kilometers per day, respectively. This finding suggests the more the driving exposure, the greater the perceived risk of using the mobile phone while driving is. Another variable investigated in the study is whether drivers often drive their vehicles during peak or off-peak hours. Figure 10 suggests drivers who often drive during the peak periods $(7 \mathrm{am}-5 \mathrm{pm})$ are associated with higher level of perceived risk than those who normally drive during off-peak periods. This observation is somewhat expected, as peak-hour driving typically requires higher level of attention on the driving tasks, which may be difficult when drivers use their mobile phones.

Overall, gender, employment status, age, education level, driving experience, daily traveled distance, and time of driving were all found to be significantly associated with perceived risk levels, as summarized in Table 3.

\subsection{Perceived risk and mobile phone use activities}

Multivariate linear regression has been successfully used in different areas of civil engineering when the explicit relationship between system parameters is mathematically required (Perkins et al. 1998; Ismeik 2009; Ismeik et al. 2010). Prior research suggested the frequency of mobile phone use while driving is associated with risk outcomes. Apparently, this usage may consequently result in a higher perceived risk. Thus, in an effort to estimate the perceived risk of phoning on road, multivariate linear regression was used to explore the functional relationships between the extent of mobile phone use and activity type, and the driver's perceived risk of phoning while driving. The resulting linear model included four independent variables that were shown to significantly affect the variation of the dependent variable; the perceived risk of phoning while driving. The model is provided by Equation (1) with regression details presented in Table 4.

$\mathrm{PR}=5.577 \mathrm{Q}_{10}+3.400 \mathrm{Q}_{11}+4.516 \mathrm{Q}_{12}+4.156 \mathrm{Q}_{13}+11.933$ 
The regression model suggests that more than $90 \%$ of the variation in driver's perceived risk (PR) is explained by four variables as included in the model. Namely; frequency of looking at the device prior to answering $\left(\mathrm{Q}_{10}\right)$, number of incoming calls answered while driving per day $\left(\mathrm{Q}_{11}\right)$, number of outgoing calls placed while driving per day $\left(\mathrm{Q}_{12}\right)$, and total time using the mobile phone while driving per day $\left(\mathrm{Q}_{13}\right)$. Generally, the driver's perceived risk increases with the increase of mobile phone activity.

\section{Strengths and limitations}

The survey method adopted in this study had several advantages, such as ease of administration and collection of valuable data coupled with reasonable participation rate $(44.9 \%)$ and large sample size (423). In addition, the assurance of anonymity and confidentiality offered by the research team lent confidence to the assumption that participants responded honestly to survey questions. Despite the contribution of the present study, the study may have some limitations to be considered in interpreting study results.

First, like most public surveys of human behavior, the use of self-report measures to assess the level of phoning while driving may not have been a reliable measure of real use. Sampling and response biases due to potential social desirability factors or inaccurate recall cannot be excluded. This is due to the negative public views of such a practice and to the illegal nature of this behavior. Although self-report measures provide a reasonable indication of people's behavior, it has been found people may under estimate their levels of mobile phone use when compared to their actual calling records (Cohen and Lemish 2003). However, given the large number of drivers admitting using their mobile phones while driving (93.1\%), social desirability effects appear minimal. Therefore, it is believed the survey provided excellent and reliable data. Second, the findings were based on self-reported survey instead of an actual onroad measurement of mobile phone use while driving. Although it was assumed most participants in the study provided honest written responses for their reactions in the survey form, it is unknown as to the extent to which this self-reported behavior truly represent real mobile phone use on the road. Third, while every attempt was made to reach a wide and diverse range of drivers across the country, the extent to which the sample of participants in this study is representative of the driving population remains debatable. Fourth, the participants of the present study were mostly males $(84.4 \%)$. This is somewhat consistent with the fact that the number of female drivers in the country is considerably smaller than male drivers. However, the high percentage of male participants may also be attributed to the difference between the two genders in terms of their willingness to participate in the study upon invitation. Fifth, a clear definition of what "using" a mobile phone while driving actually means was not given specifically in the questionnaire. The definition is open to dialing, talking, receiving calls, searching for a number, reaching for a device, writing and reading text messages, playing games, looking through photos, or navigating roads. However, due to the definition of questions $\mathrm{Q}_{10}, \mathrm{Q}_{11}$, and $\mathrm{Q}_{12}$, it is believed that most of participants thought mostly of answering, placing calls, and talking over the mobile phone. Last, the study did not attempt to ask if the participant was ever involved in a crash, with injuries or fatalities, as a result of using a mobile phone in motion. It was thought the driver would not respond to this question reliably and honestly. Thus, it was not possible to link real crash risk on the road to mobile phone related activities. 


\section{Conclusions}

Similar to many countries, the growth of mobile telecommunications in Jordan has been steadily increasing during the last decade. Thus, the phenomenon of using a mobile phone while driving has become a concern to highway authorities. Although there is a general appreciation of the problem, its gravity and potential impacts on traffic safety are still not known. Consequently, there is little information that can be used in developing remedies and countermeasures. The current study conducted a survey of drivers who use their mobile phones while driving in an attempt to develop a better understanding of this safety phenomenon.

The overall pattern of survey results suggest that, in general, mobile phone use on road is very high among drivers; thus, representing a significant potential hazard to all road users. Although the majority of drivers appear to acknowledge the associate risk involved in phoning while driving, yet they still continue to use their mobile phones in motion extensively.

The study found those who perceived more risk associated with their mobile phone use while driving involved: 1) more male drivers; 2) drivers in their early 20s; and 3) drivers who are mostly students. The study revealed that drivers with less driving experience (including novice drivers) and limited driving exposure perceive less risk of phoning while driving. Findings confirmed driver's perceived risk of phoning while driving is largely (and directly) related to the extent of mobile phone use on the road.

\section{Recommendations}

In order to reduce the hazardous effects of phoning while driving and to enhance the traffic safety in the country, an immediate implementation of a comprehensive program through education, engineering, and enforcement is necessary among the driving and non-driving public. This is achieved through the following three initiatives.

\subsection{Education initiative}

The study represents an attempt to obtain detailed data on drivers' engagement with mobile phones while driving. The authors hope this valuable data can be used to help the traffic safety community in addressing this important safety concern through well-designed educational programs, specific countermeasures, and customized intervention strategies and policies, which minimize the illegal practice of phoning while driving.

Campaigns and prevention initiatives to reduce mobile phone use while driving, independent of risk perception, should focus on changing drivers' attitudes and behavior to become less supportive of such practice. Educational programs that usually focused on increasing awareness and knowledge of risk, without seeking behavior change, generally failed in reducing crashes (Ivers et al. 2009). Direct initiatives should promote safe practices, such as limiting mobile phone use while driving, placing calls only when vehicles are not in motion, reducing speed while conversation, increasing following distance, reducing conversation length, avoiding conversations under poor weather conditions, while in heavy traffic or in unfamiliar areas, when driving at night, on winding or curved roads, and around schools (Young and Lenne 2010). Such initiatives should be conducted on a regular basis and should be combined with proper traffic regulations, and coordinated and sustained enforcement activities throughout the country. 
Effective interventions and awareness campaigns, developed to reduce the adverse effects of phoning while driving, should target male college students aged 21 to 30 years with 6 to 11 years of driving experience and who travel about $41 \mathrm{~km}$ daily. This specific target population constitutes the largest proportion of drivers who are frequent mobile phone users.

Although educational efforts may not be effective for all drivers, some impact on some drivers may be considered valuable. These educational efforts should be focused on new drivers who have not yet established firm beliefs and habitual behaviors compared to experienced mobile phone users who have well-established belief systems which are difficult to change (Wogalter and Mayhorn 2005). Therefore, the authors recommend increasing the awareness of the problem among the driving population, particularly young and to be drivers, through driver instruction books, and in curriculums and safety classes for high school and college students.

\subsection{Engineering initiative}

The technological solutions, currently being developed by researchers, to change mobile phones so they cannot be used when vehicles are in motion, may be a vital option to reduce the crash risk related to phoning while driving. For example, a telephone answering system which warns users the person they are calling is driving, or adaptive technology that filters or delays calls according to the driving context, or a system which detects the driver's use of a mobile phone and notify the vehicle plate number information to the police for legislative action against the driver, seem to provide potential solutions to the safety issues raised by phoning while driving (Brusque and Alauzet 2008; Abdul Shabeer and Wahidabanu 2012). In addition, manufacturers may develop "vehicle" mode, similar in concept to "flight" mode, which turns on automatically when the device is in use by the driver on the road. Under the "vehicle" mode, the device simply locks out all communication features as detected by GPS (Dingus et al. 2011).

\subsection{Enforcement initiative}

Legislation prohibition of all types of mobile phone use while driving, paired with effective enforcement and strong penalties, would be an appropriate solution for this risky behavior for the sake of traffic safety of people. Well-planned initiatives, illustrating the hazardous effect of this practice, would gain momentum for public approval for such legislation. In addition, automobile insurance companies can raise premiums for drivers who use mobile phones while driving, or lower premiums for drivers who do not use their mobile phones on road. Then, drivers would have a monetary incentive for not using the mobile phones when driving.

\section{Future research directions}

The lack of local crash data is preventing an accurate assessment of the number of people involved in crashes caused, or contributed to, by drivers who are using their mobile phones. Therefore, there is a need for developing and implementing methods to record whether a driver involved in a crash had a mobile phone, and whether it was being used. As a first step in routine crash investigations, the crash reporting system should be amended to record data about mobile phone use, although it will often not be easy for the police to identify whether a driver was using a mobile phone, as anyone who was doing so is unlikely to readily admit to it. Furthermore, tracking mobile phone call records, with the assistance of service providers or via GPS monitoring, could provide more reliable and valuable data on the real use of mobile phones during or before crashes. Once available, such data should be collected on a national scale, as the first most important step, in order to conduct additional research which 
accurately correlates actual crashes and associated risk resulting from mobile phone use in motion.

Further comprehensive and observational surveys, with larger study populations and more complex measurement protocols, to record mobile phone use by drivers should be administrated on a regular basis, to confirm the initial findings of this research and to measure the effectiveness of the suggested three initiatives.

As younger people are found to use their mobile phones while driving more frequently than other groups, use of a specific youth sample may provide valuable information on how to reduce this behavior among this age group.

Additional well-designed research is needed to reduce the associated risk related to phoning while driving, and how this risk is minimized. Such research would provide an evidence-base for road safety policy with the consequent benefits of reducing mobile phone use while driving among the public.

\section{Acknowledgments}

The first author is grateful to The University of Jordan during which part of this study was conducted and for granting his leave. The additional research support complemented by Australian College of Kuwait is equally acknowledged. The kind assistance provided by the Traffic Institute of Jordan is recognized. The thoughtful comments and suggestions of the anonymous reviewers are appreciated. 


\section{References}

Abdul Shabeer, H., and Wahidabanu, R. S. D. (2012). Averting mobile phone use while driving and technique to locate the mobile phone used vehicle. Procedia Engineering, 30: 623630 .

Ashteyat, A. M., Ismeik, M., and Ramadan, K. Z. (2012). Strength development models of concrete with silica fume as fine aggregate replacement material. Global Journal of Researches in Engineering, 12(2): 27-31.

Ashteyat, A. M., Haddad, R. H., and Ismeik, M. (2014). Prediction of mechanical properties of post-heated self-compacting concrete using nondestructive tests. European Journal of Environmental and Civil Engineering, 18(1): 1-10.

Backer-Grondahl, A., and Sagberg, F. (2011). Driving and telephoning: Relative accident risk when using hand-held and hands-free mobile phones. Safety Science, 49(2): 324-330.

Beck, K. H., Yan, F., and Wang, M. O. (2007). Cell phone users, reported crash risk, unsafe driving behaviors and dispositions: A survey of motorists in Maryland. Journal of Safety Research, 38(6): 683-688.

Bellinger, D. B., Budde, B. M, Machida, M., Richardson, G. B, and Berg, W. P. (2009). The effect of cellular telephone conversation and music listening on response time in braking. Transportation Research Part F, 12(6): 441-451.

Braitman, K. A., and McCartt, A. T. (2010). National reported patterns of driver cell phone use in the United States. Traffic Injury Prevention, 11(6): 543-548.

Brusque, C., and Alauzet, A. (2008). Analysis of the individual factors affecting mobile phone use while driving in France: Socio-demographic characteristics, car and phone use in professional and private contexts. Accident Analysis and Prevention, 40(1): 35-44.

Caird, J. K., Johnston, K. A., Willness, C. R., Asbridge, M., and Steel, P. (2014). A metaanalysis of the effects of texting on driving. Accident Analysis and Prevention, 71: 311-318.

Cohen, A. A., and Lemish, D. (2003). Real time and recall measures of mobile phone use: Some methodological concerns and empirical applications. New Media and Society, 5(2): 167-183.

Collet, C., Guillot, A., and Petit, C. (2010a). Phoning while driving I: A review of epidemiological, psychological, behavioural and physiological studies. Ergonomics, 53(5): 589-601.

Collet, C., Guillot, A., and Petit, C. (2010b). Phoning while driving II: A review of driving conditions influence. Ergonomics, 53(5): 602-616.

Crundall, D., Bains, M., Chapman, P., and Underwood, G. (2005). Regulating conversation during driving: A problem for mobile telephones? Transportation Research Part F, 8(3): 197211. 
Dingus, T. A., Hanowski, R. J., and Klauer, S. G. (2011). Estimating crash risk. Ergonomics in Design: The Quarterly of Human Factors Applications, 19(4): 8-12.

Fitch, G. M., Hanowski, R. J., and Guo., F. (2015). The risk of a safety-critical event associated with mobile device use in specific driving contexts. Traffic Injury Prevention, 16(2): 124-132.

Gras, M. E., Cunill, M., Sullman, M. J. M., Planes, M., Aymerich, M., and Font-Mayolas, S. (2007). Mobile phone use while driving in a sample of Spanish university workers. Accident Analysis and Prevention, 39(2): 347-355.

Green, P. (2007). Where do drivers look while driving (and for how long)? In: Dewar, R. E., Olsen, R. (Eds.), Human Factors in Traffic Safety, Second Ed., Lawyers and Judges Publishing, Tucson, AZ, pp. 57-82.

Hafetz, J. S., Jacobsohn, L. S., Garcia-Espana, J. F., Curry, A. E., and Winston, F. K. (2010). Adolescent drivers' perceptions of the advantages and disadvantages of abstention from invehicle cell phone use. Accident Analysis and Prevention, 42(6): 1570-1576.

Hallett, C., Lambert, A., and Regan, M. A. (2011). Cell phone conversing while driving in New Zealand: Prevalence, risk perception and legislation. Accident Analysis and Prevention, 43(3): 862-869.

Harrison, M. A. (2011). College students' prevalence and perceptions of text messaging while driving. Accident Analysis and Prevention, 43(4): 1516-1520.

Hickman, J. S., and Hanowski, R. J. (2012). An assessment of commercial motor vehicle driver distraction using naturalistic driving data. Traffic Injury Prevention, 13(6): 612-619.

Holland, C., and Rathod, V. (2013). Influence of personal mobile phone ringing and usual intention to answer on driver error. Accident Analysis and Prevention, 50(1): 793-800.

Irwin, C., Monement, S., and Desbrow, B. (2015). The influence of drinking, texting and eating on simulated driving performance. Traffic Injury Prevention, 16(2): 116-123.

Ismeik, M. (2009). Effect of mineral admixtures on mechanical properties of high strength concrete made with locally available materials. Jordan Journal of Civil Engineering, 3(1): 7890 .

Ismeik, M., and Al-Kaisy, A. (2010). Characterization of cell phone use while driving in Jordan. Transport, 25(3): 252-261.

Ismeik, M., Jrew, B., and Abbas, N. (2010). Development of driver behavior's accident prediction models. International Journal of Natural and Engineering Sciences, 4(3): 61-70.

Ivers, R., Senserrick, T., Boufous, S., Stevenson, M., Chen, H., Woodward, M., and Norton, R. (2009). Novice drivers' risky driving behavior, risk perception, and crash risk: Findings from the drive study. American Journal of Public Health, 99(9): 1638-1644. 
Klauer, S. G., Dingus, T. A., Neale, V. L., Sudweeks, J. D., and Ramsey, D. J. (2006). The impact of driver inattention on near-crash/crash risk: An analysis using the 100-car naturalistic driving study data. Report No. DOT HS 810 594, National Highway Traffic Safety Administration, Washington DC. Retrieved from:

http://www.nhtsa.gov/DOT/NHTSA/NRD/Multimedia/PDFs/Crash\%20Avoidance/Driver\%2 0Distraction/810594.pdf.

Klauer, S. G., Guo, F., Simons-Morton, B. G., Ouimet, M. C., Lee, S. E., and Dingus, T. A. (2014). Distracted driving and risk of road crashes among novice and experienced drivers. New England Journal of Medicine, 370(1): 54-59.

Laberge-Nadeau, C., Maag, U., Bellavance, F., Lapierre, S. D., Desjardins, D., Messier, S, and Saidi, A. (2003). Wireless telephones and the risk of road crashes. Accident Analysis and Prevention, 35(5): 649-660.

McCartt, A. T., Hellinga, L. A., and Bratiman, K. A. (2006). Cell phones and driving: Review of research. Traffic Injury Prevention, 7(2): 89-106.

McCartt, A. T., Hellinga, L. A., Strouse, L. M., and Farmer, C. M. (2010). Long-term effects of handheld cell phone laws on driver handheld cell phone use. Traffic Injury Prevention, 11(2): 133-141.

McClave, J. T. and Sincich, T. (2006). Statistics. Prentice-Hall, Upper Saddle River, NJ.

McEvoy, S. P., Stevenson, M. R., and Woodward, M. (2006). Phone use and crashes while driving: A representative survey of drivers in two Australian states. Medical Journal of Australia, 185(11-12): 630-634.

Nelson, E., Atchley, P., and Little, T. D. (2009). The effects of perception of risk and importance of answering and initiating a cellular phone call while driving. Accident Analysis and Prevention, 41(3): 438-444.

Nemme, H.E., and White, K. M. (2010). Texting while driving: Psychosocial influences on young people's texting intentions and behaviour. Accident Analysis and Prevention, 42 (4): 1257-1265.

Nurullah, A. S., Thomas, J., and Vakilian, F. (2013). The prevalence of cell phone use while driving in a Canadian province. Transportation Research Part F, 19(1): 52-62.

Olson, R. L., Hanowski, R. J., Hickman, J. S., and Bocanegra, J. (2009). Driver distraction in commercial vehicle operations. Report No. FMCSA-RRR-09-042, U.S. Department of Transportation, Washington DC. Retrieved from:

http://www.fmcsa.dot.gov/sites/fmcsa.dot.gov/files/docs/FMCSA-RRR-09-042.pdf.

Perkins, S., Ismeik, M., and Fogelsong, M. (1998). Mechanical response of a geosyntheticreinforced pavement system to cyclic loading. Proceedings of the Fifth International Conference on the Bearing Capacity of Roads and Airfields (BCRA '98), July 6-8, 1998, Trondheim, Norway, 3: 1503-1512. 
Poysti, L., Rajalin, S., and Summala, H. (2005). Factors influencing the use of cellular (mobile) phone during driving and hazards while using it. Accident Analysis and Prevention, 37(1): 47-51.

Redelmeier, D. A., and Tibshirani, R.J. (1997). Association between cellular-telephone calls and motor vehicle collisions. New England Journal of Medicine, 336(7): 453-458.

Schlehofer, M. M., Thompson, S. C., Ting, S., Ostermann, S., Nierman, A., and Skenderian, J. (2010). Psychological predictors of college students' cell phone use while driving. Accident Analysis and Prevention, 42(4): 1107-1112.

Seo, D., and Torabi, M. R. (2004). The impact of in-vehicle cell-phone use on accidents or near-accidents. Journal of American College Health, 53(3): 101-107.

Simons-Morton, B. G., Guo, F., Klauer, S. G., Ehsani, J. P., and Pradhan, A. K. (2014). Keep your eyes on the road: Young driver crash risk increases according to duration of distraction. Journal of Adolescent Health, 54(5): S61-S67.

Stavrinos, D., Byington, K. W., and Schwebel, D. C. (2011). Distracted walking: Cell phones increase injury risk for college pedestrians. Journal of Safety Research, 42(2): 101-107.

TRC, Telecommunications Regulatory Commission of Jordan. (2014). Retrieved from: http://www.trc.gov.jo/index.php?option=com_content\&task=view\&id=2600\&Itemid=508\&la ng=english\&lang=english\&lang=english \#.

Troglauer, T., Hels, T., and Christens, P. F. (2006). Extent and variations in mobile phone use among drivers of heavy vehicles in Denmark. Accident Analysis and Prevention, 38(1): 105111.

Walsh, S. P., White, K. M., Hyde, M. K., and Watson, B. (2008). Dialling and driving: Factors influencing intentions to use a mobile phone while driving. Accident Analysis and Prevention 40(6): 1893-1900.

Wilson, J. Fang, M., Wiggins, S., and Cooper, P. (2003). Collision and violation involvement of drivers who use cellular telephones. Traffic Injury Prevention, 4(1): 45-52.

Wogalter, M. S., and Mayhorn, C. B. (2005). Perceptions of driver distraction by cellular phone users and nonusers. Human Factors, 47(2), 455-467.

Young, K. L., and Lenne, M. G. (2010). Driver engagement in distracting activities and the strategies used to minimise risk. Safety Science, 48(3): 326-332.

Young, K. L., Salmon, P. M., and Cornelissen, M. (2013). Missing links? The effects of distraction on driver situation awareness. Safety Science, 56: 36-43.

Zhao, N., Reimer, B., Mehler, B., D'Ambrosio, L. A., and Coughlin, J. F. (2013). Selfreported and observed risky driving behaviors among frequent and infrequent cell phone users. Accident Analysis and Prevention, 61: 71-77. 


\section{List of tables}

Table 1. Questionnaire and related response formats

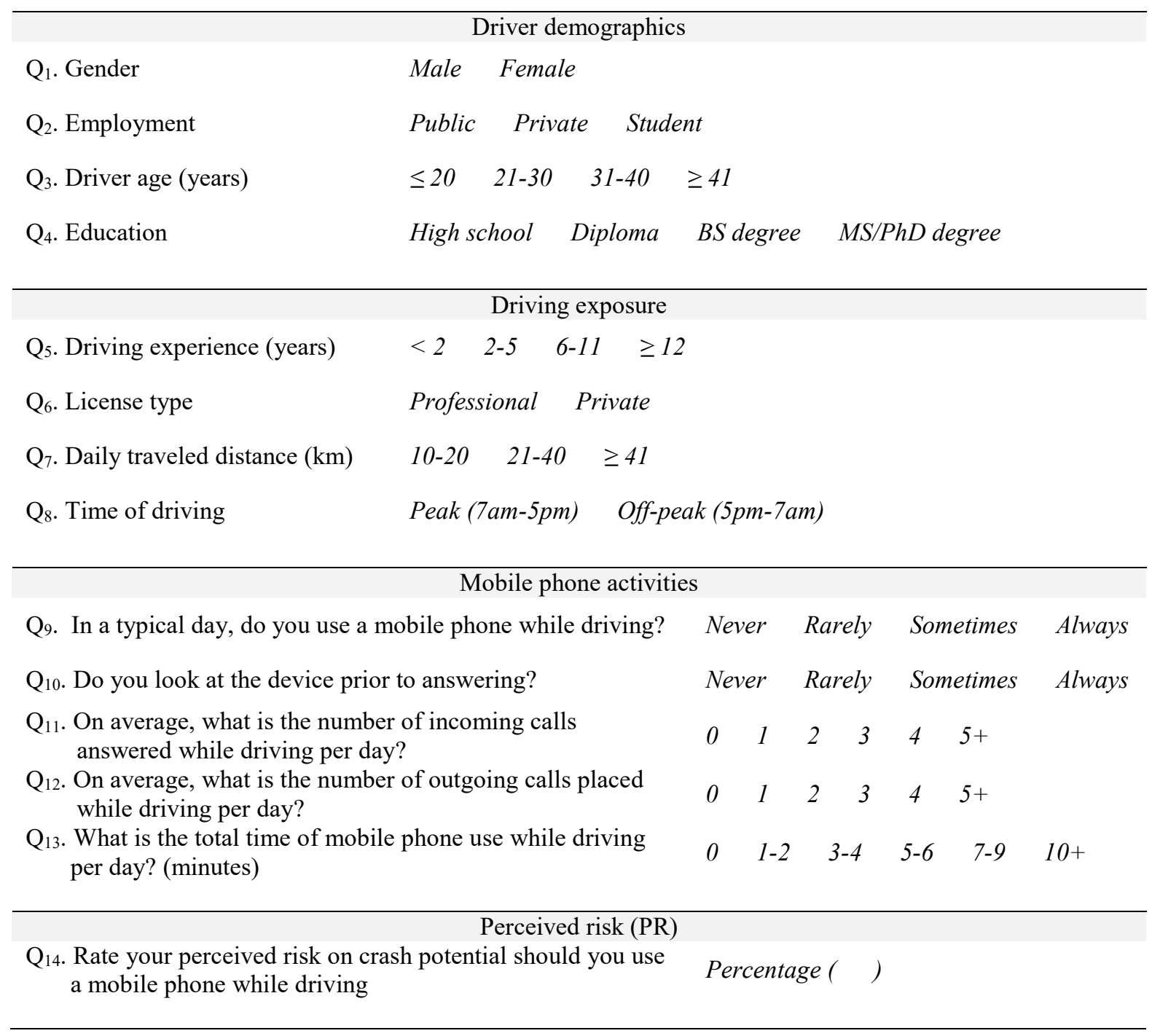


Table 2. Logistic regression and Pearson Chi-square test results

\begin{tabular}{|c|c|c|c|c|c|c|c|}
\hline \multirow{2}{*}{ Characteristic } & \multicolumn{2}{|c|}{ Users (394) } & \multicolumn{2}{|c|}{ Nonusers (29) } & \multirow{2}{*}{$95 \% \mathrm{CI}$} & \multirow{2}{*}{ OR } & \multirow{2}{*}{$\chi^{2}$} \\
\hline & Number & Percentage & Number & Percentage & & & \\
\hline \multicolumn{8}{|c|}{ Driver demographics } \\
\hline \multicolumn{8}{|l|}{ Gender } \\
\hline Male & 346 & 96.9 & 11 & 3.1 & $3.307-49.804$ & $12.835^{* * *}$ & \multirow{2}{*}{$51.049^{* * *}$} \\
\hline Female & 48 & 72.7 & 18 & 27.3 & & 1 & \\
\hline \multicolumn{8}{|l|}{ Employment } \\
\hline Public sector & 119 & 95.2 & 6 & 4.8 & $0.153-4.602$ & 0.840 & \multirow{3}{*}{$19.007^{* * *}$} \\
\hline Private sector & 89 & 84.0 & 17 & 16.0 & $0.026-0.604$ & $0.126^{* *}$ & \\
\hline Student & 186 & 96.9 & 6 & 3.1 & & 1 & \\
\hline \multicolumn{8}{|l|}{ Driver age (years) } \\
\hline $18-20$ & 30 & 83.3 & 6 & 16.7 & $0.287-30.623$ & 2.966 & \multirow{4}{*}{$18.418^{* * *}$} \\
\hline $21-30$ & 236 & 97.5 & 6 & 2.5 & $1.076-34.174$ & $6.063^{*}$ & \\
\hline $31-40$ & 97 & 89.0 & 12 & 11.0 & $0.271-8.776$ & 1.544 & \\
\hline $41+$ & 31 & 86.1 & 5 & 13.9 & & 1 & \\
\hline \multicolumn{8}{|l|}{ Education } \\
\hline High school & 48 & 90.6 & 5 & 9.4 & $0.094-10.201$ & 0.978 & \multirow{4}{*}{$19.276^{* * *}$} \\
\hline Diploma & 95 & 85.6 & 16 & 14.4 & $0.044-2.099$ & 0.303 & \\
\hline $\mathrm{BS}$ & 227 & 97.8 & 5 & 2.2 & $0.665-31.210$ & 4.557 & \\
\hline $\mathrm{MS} / \mathrm{PhD}$ & 24 & 88.9 & 3 & 11.1 & & 1 & \\
\hline \multicolumn{8}{|c|}{ Driving exposure } \\
\hline \multicolumn{8}{|l|}{ Experience (years) } \\
\hline$<2$ & 30 & 78.9 & 8 & 21.1 & $0.026-0.775$ & $0.142^{*}$ & \multirow{4}{*}{$17.363^{* * *}$} \\
\hline $2-5$ & 48 & 88.9 & 6 & 11.1 & $0.006-0.253$ & $0.040^{* * *}$ & \\
\hline $6-11$ & 157 & 96.9 & 5 & 3.1 & $0.174-3.519$ & 0.783 & \\
\hline $12+$ & 159 & 94.1 & 10 & 5.9 & & 1 & \\
\hline \multicolumn{8}{|l|}{ License type } \\
\hline Professional & 54 & 91.5 & 5 & 8.5 & $0.166-3.233$ & 0.733 & \multirow{2}{*}{0.281} \\
\hline Private & 340 & 93.4 & 24 & 6.6 & & 1 & \\
\hline \multicolumn{8}{|c|}{ Daily traveled distance $(\mathrm{km})$} \\
\hline $10-20$ & 102 & 87.2 & 15 & 12.8 & $0.222-4.273$ & 0.973 & \multirow{3}{*}{$11.570^{* *}$} \\
\hline $21-40$ & 94 & 92.2 & 8 & 7.8 & $0.024-0.766$ & $0.135^{*}$ & \\
\hline $41+$ & 198 & 97.1 & 6 & 2.9 & & 1 & \\
\hline \multicolumn{8}{|l|}{ Time of driving } \\
\hline Peak & 256 & 93.8 & 17 & 6.2 & $0.472-4.363$ & 1.435 & \multirow{2}{*}{0.477} \\
\hline Off-peak & 138 & 92.0 & 12 & 8.0 & & 1 & \\
\hline
\end{tabular}


Table 3. Distribution of risk perception levels

\begin{tabular}{|c|c|c|c|c|}
\hline \multirow{2}{*}{ Characteristic } & \multicolumn{3}{|c|}{ Perceived risk } & \multirow{2}{*}{$\chi^{2}$} \\
\hline & Low & Moderate & High & \\
\hline \multicolumn{5}{|c|}{ Driver demographics } \\
\hline \multicolumn{5}{|l|}{ Gender } \\
\hline Male & $9(2.5 \%)$ & $152(42.6 \%)$ & $196(54.9 \%)$ & \multirow{2}{*}{$68.703^{* * *}$} \\
\hline Female & $16(24.2 \%)$ & $41(62.2 \%)$ & $9(13.6 \%)$ & \\
\hline \multicolumn{5}{|l|}{ Employment } \\
\hline Public sector & $8(6.4 \%)$ & $44(35.2 \%)$ & $73(58.4 \%)$ & \multirow{3}{*}{$31.054^{* * *}$} \\
\hline Private sector & $12(11.3 \%)$ & $65(61.3 \%)$ & $29(27.4 \%)$ & \\
\hline Student & $5(2.6 \%)$ & $84(43.8 \%)$ & $103(53.6 \%)$ & \\
\hline \multicolumn{5}{|l|}{ Age } \\
\hline $18-20$ & $5(13.9 \%)$ & $26(72.2 \%)$ & $5(13.9 \%)$ & \multirow{4}{*}{$49.489^{* * *}$} \\
\hline $21-30$ & $6(2.5 \%)$ & $95(39.2 \%)$ & $141(58.3 \%)$ & \\
\hline $31-40$ & $6(5.5 \%)$ & $56(51.4 \%)$ & $47(43.1 \%)$ & \\
\hline $41+$ & $8(22.3 \%)$ & $16(44.4 \%)$ & $12(33.3 \%)$ & \\
\hline \multicolumn{5}{|l|}{ Education } \\
\hline High school & $6(11.3 \%)$ & $29(54.7 \%)$ & $18(34.0 \%)$ & \multirow{4}{*}{$31.461^{* * *}$} \\
\hline Diploma & $6(5.4 \%)$ & $39(35.1 \%)$ & $66(59.5 \%)$ & \\
\hline $\mathrm{BS}$ & $7(3.0 \%)$ & $110(47.4 \%)$ & $115(49.6 \%)$ & \\
\hline $\mathrm{MS} / \mathrm{PhD}$ & $6(22.2 \%)$ & $15(55.6 \%)$ & $6(22.2 \%)$ & \\
\hline \multicolumn{5}{|c|}{ Driving exposure } \\
\hline \multicolumn{5}{|l|}{ Experience (years) } \\
\hline$<2$ & $6(15.8 \%)$ & $23(60.5 \%)$ & $9(23.7 \%)$ & \multirow{4}{*}{$23.787^{* *}$} \\
\hline $2-5$ & $5(9.3 \%)$ & $27(50.0 \%)$ & $22(40.7 \%)$ & \\
\hline $6-11$ & $5(3.1 \%)$ & $61(37.7 \%)$ & $96(59.2 \%)$ & \\
\hline $12+$ & $9(5.3 \%)$ & $82(48.5 \%)$ & $78(46.2 \%)$ & \\
\hline \multicolumn{5}{|l|}{ License type } \\
\hline Professional & $6(10.2 \%)$ & $23(39.0 \%)$ & $30(50.8 \%)$ & \multirow{2}{*}{2.848} \\
\hline Private & $19(5.2 \%)$ & $170(46.7 \%)$ & $175(48.1 \%)$ & \\
\hline \multicolumn{5}{|c|}{ Daily traveled distance $(\mathrm{km})$} \\
\hline $10-20$ & $14(12.0 \%)$ & $60(51.3 \%)$ & $43(36.7 \%)$ & \multirow{3}{*}{$53.207^{* * *}$} \\
\hline $21-40$ & $5(4.9 \%)$ & $68(66.7 \%)$ & $29(28.4 \%)$ & \\
\hline $41+$ & $6(2.9 \%)$ & $65(31.9 \%)$ & $133(65.2 \%)$ & \\
\hline \multicolumn{5}{|l|}{ Time of driving } \\
\hline Peak & $12(4.4 \%)$ & $116(42.5 \%)$ & $145(53.1 \%)$ & \multirow{2}{*}{$8.082^{*}$} \\
\hline Off-peak & $13(8.7 \%)$ & $77(51.3 \%)$ & $60(40.0 \%)$ & \\
\hline
\end{tabular}


Table 4. Multivariate linear regression results

\begin{tabular}{ccccc}
\hline \multicolumn{5}{c}{ Model characteristics } \\
$\mathrm{R}$ & $\mathrm{R}^{2}$ & Standard error & F-value & $\mathrm{p}$-value \\
\hline 0.951 & 0.905 & 5.266 & 996.884 & $<0.001$ \\
& & & \\
\hline & & Statistical parameters \\
Variable & Coefficient & Standard error & t-value & p-value \\
\hline $\mathrm{Q}_{10}$ & 5.577 & 0.279 & 19.978 & $<0.001$ \\
$\mathrm{Q}_{11}$ & 3.400 & 0.213 & 15.946 & $<0.001$ \\
$\mathrm{Q}_{12}$ & 4.516 & 0.234 & 19.287 & $<0.001$ \\
$\mathrm{Q}_{13}$ & 4.156 & 0.282 & 14.762 & $<0.001$ \\
Constant & 11.933 & 0.891 & 13.386 & $<0.001$ \\
\hline
\end{tabular}




\section{List of figures}

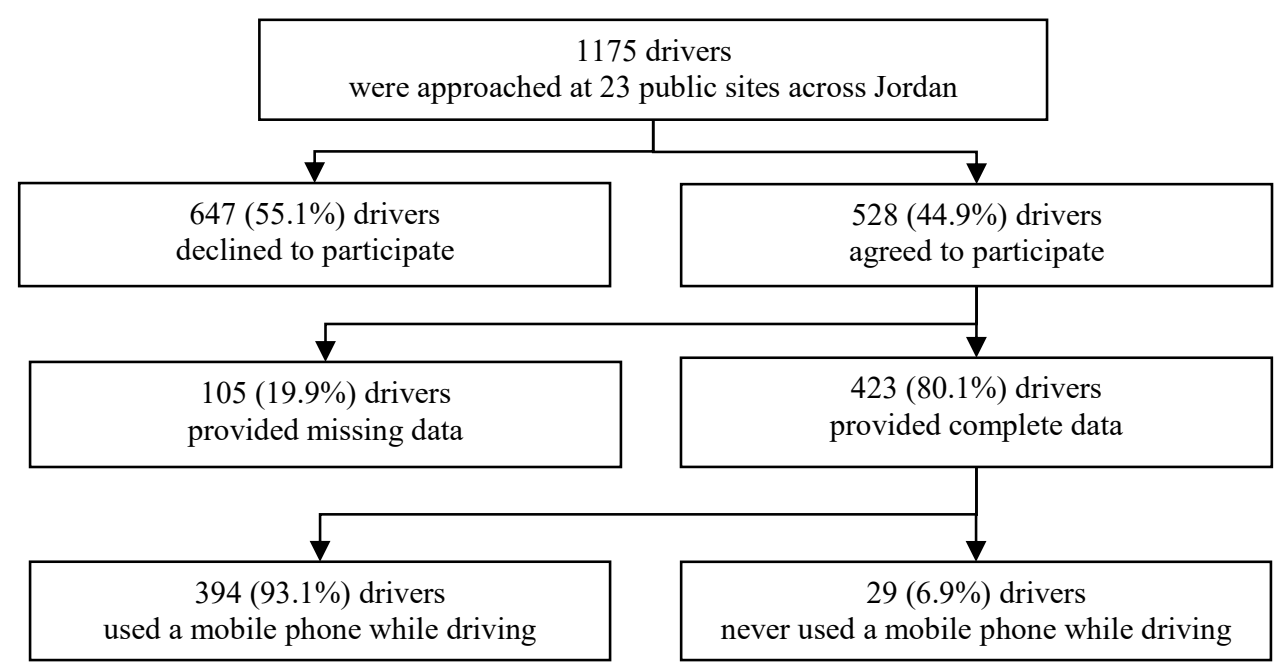

Figure 1. Survey response breakdown 


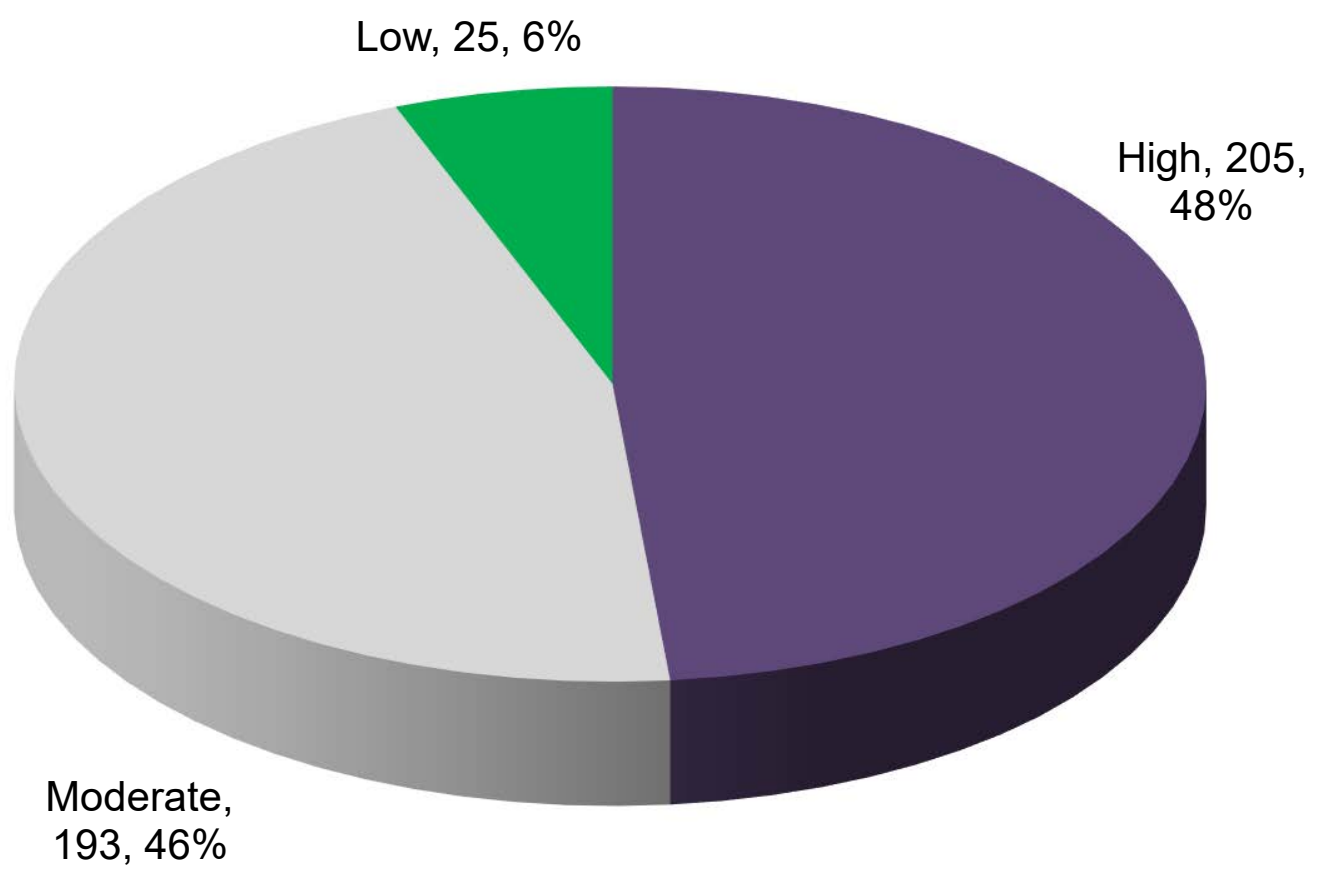

Figure 2. Distribution of survey drivers' perceived risk levels 


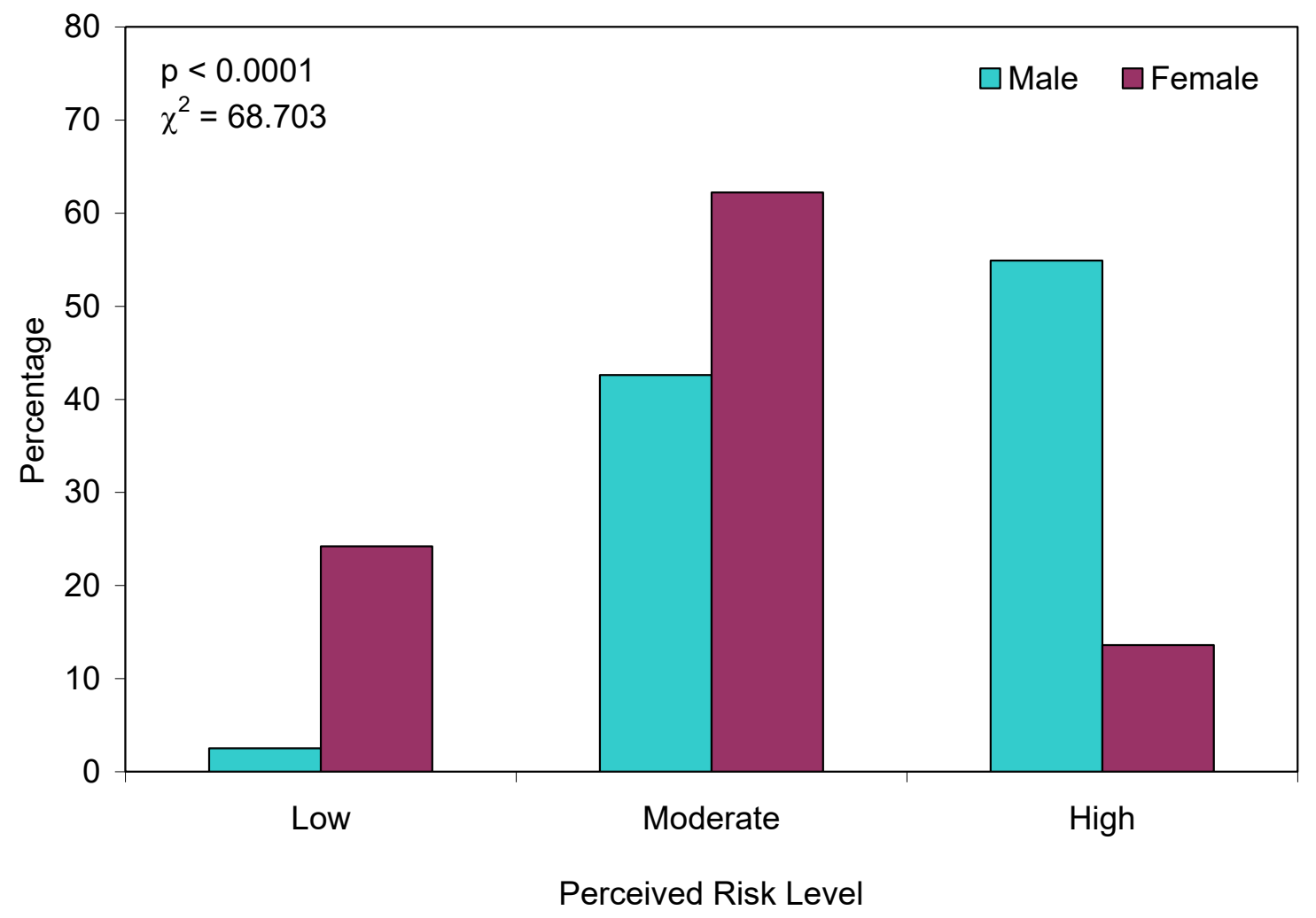

Figure 3. Risk perception distribution by driver gender 


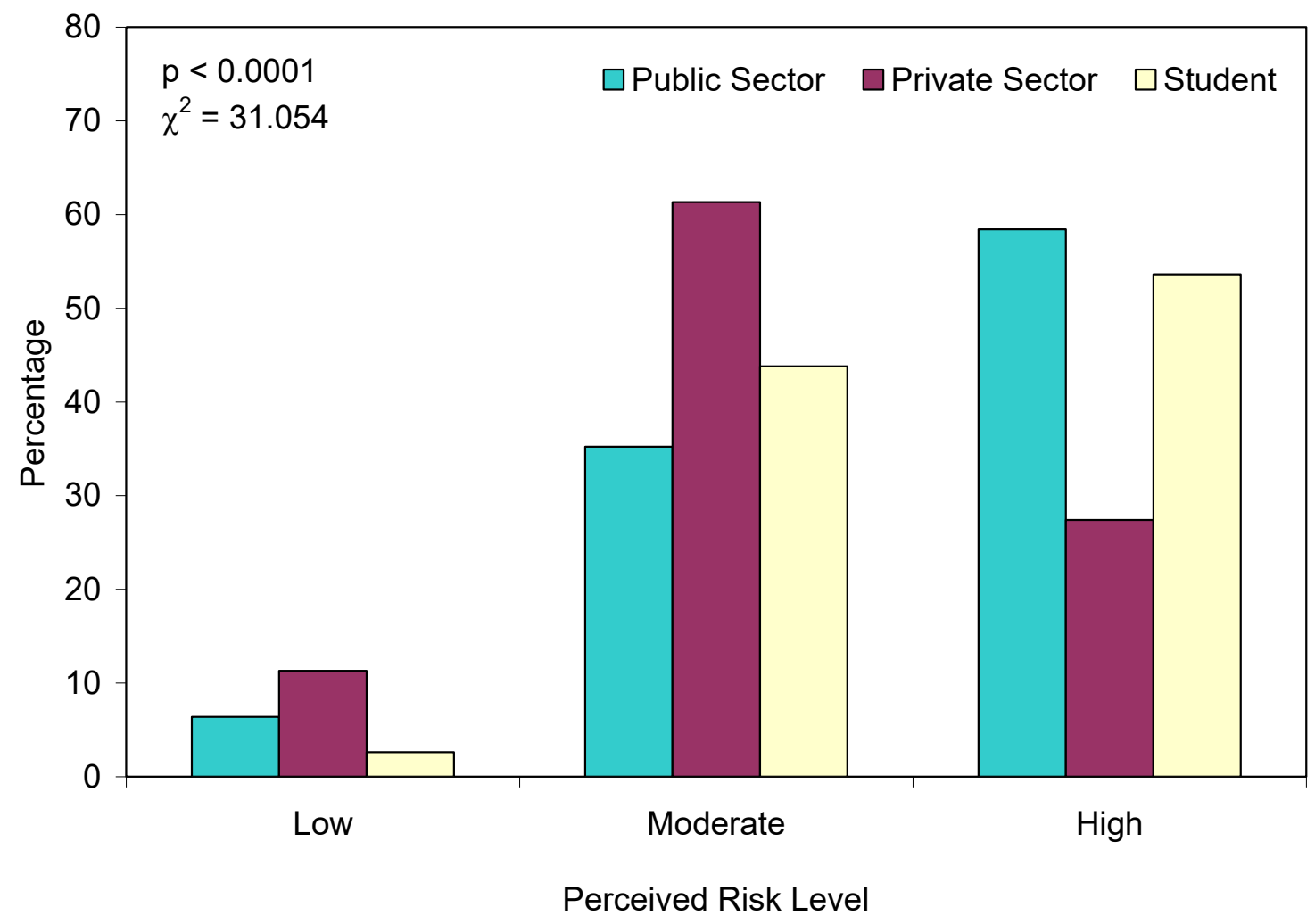

Figure 4. Risk perception distribution by driver employment status 


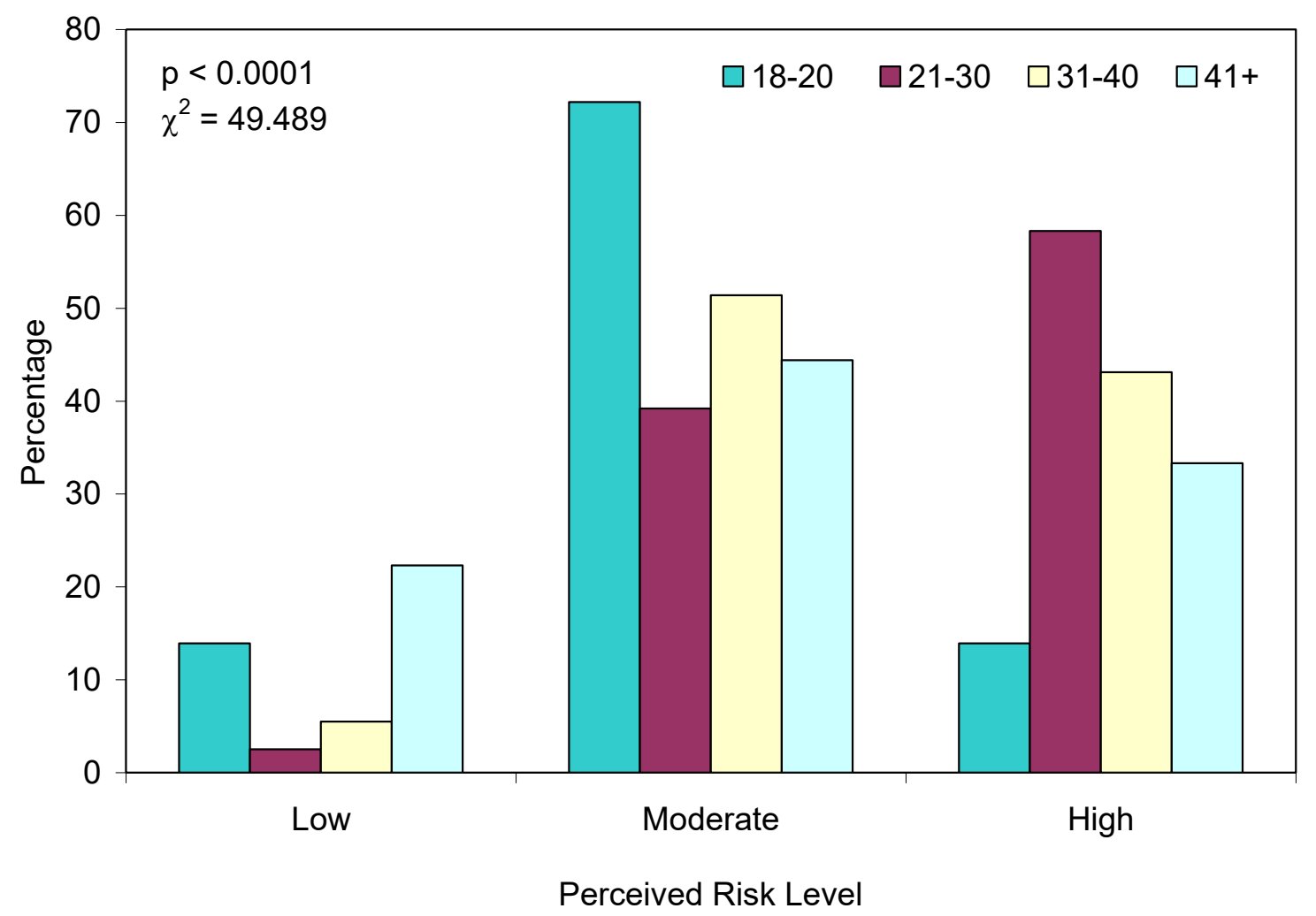

Figure 5. Risk perception distribution by driver age (years) 


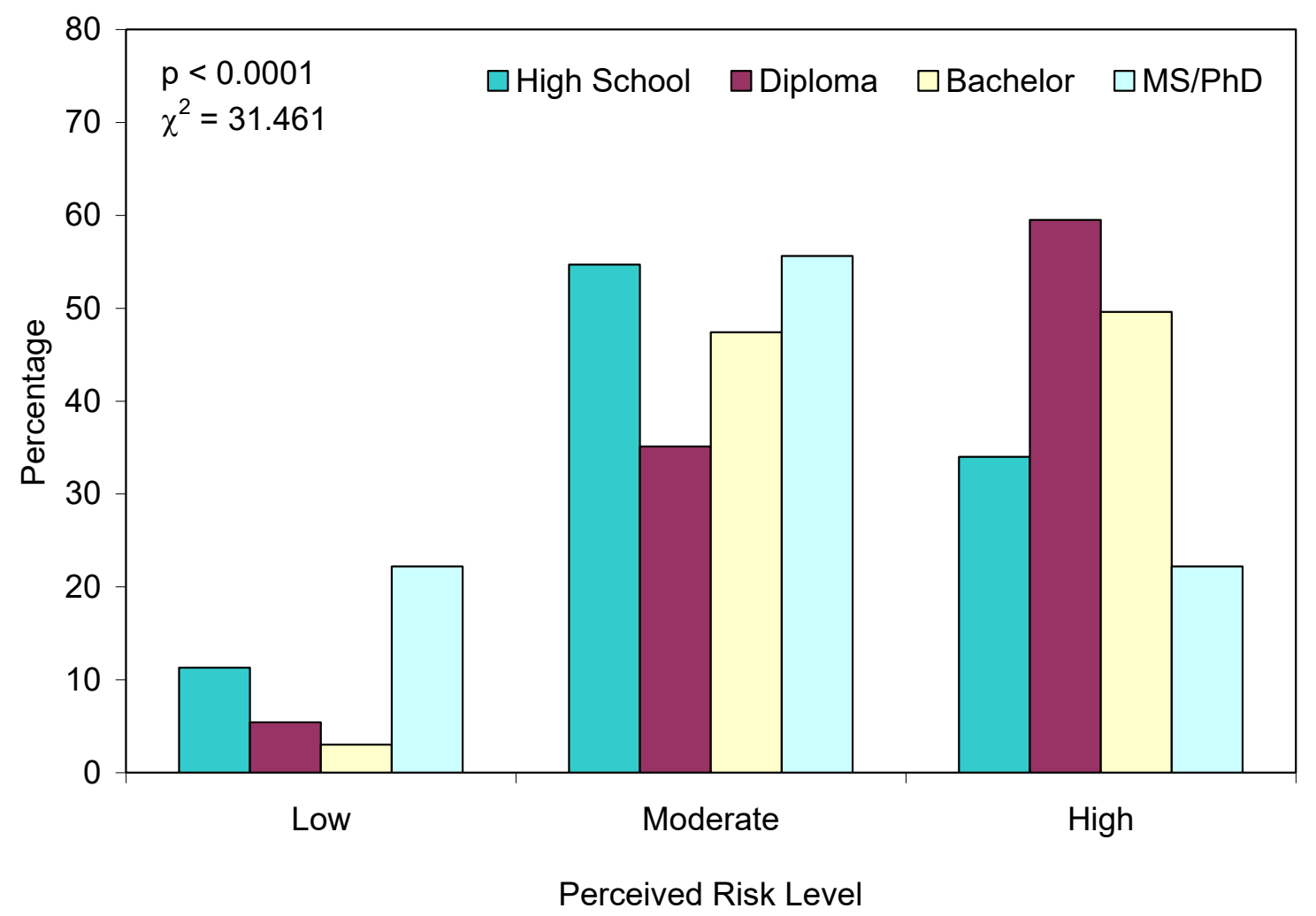

Figure 6 . Risk perception distribution by driver education level 


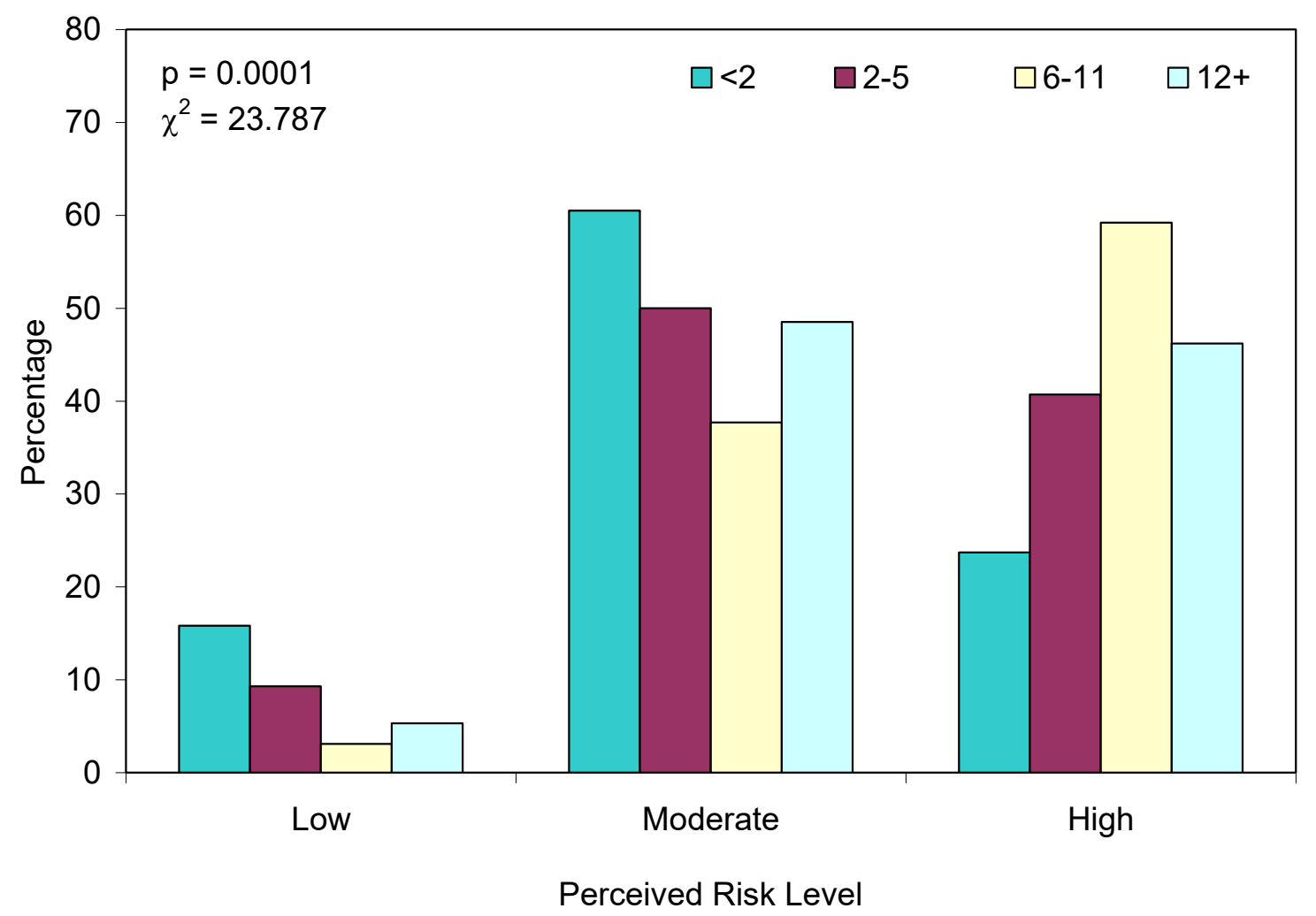

Figure 7. Risk perception distribution by driver driving experience (years) 


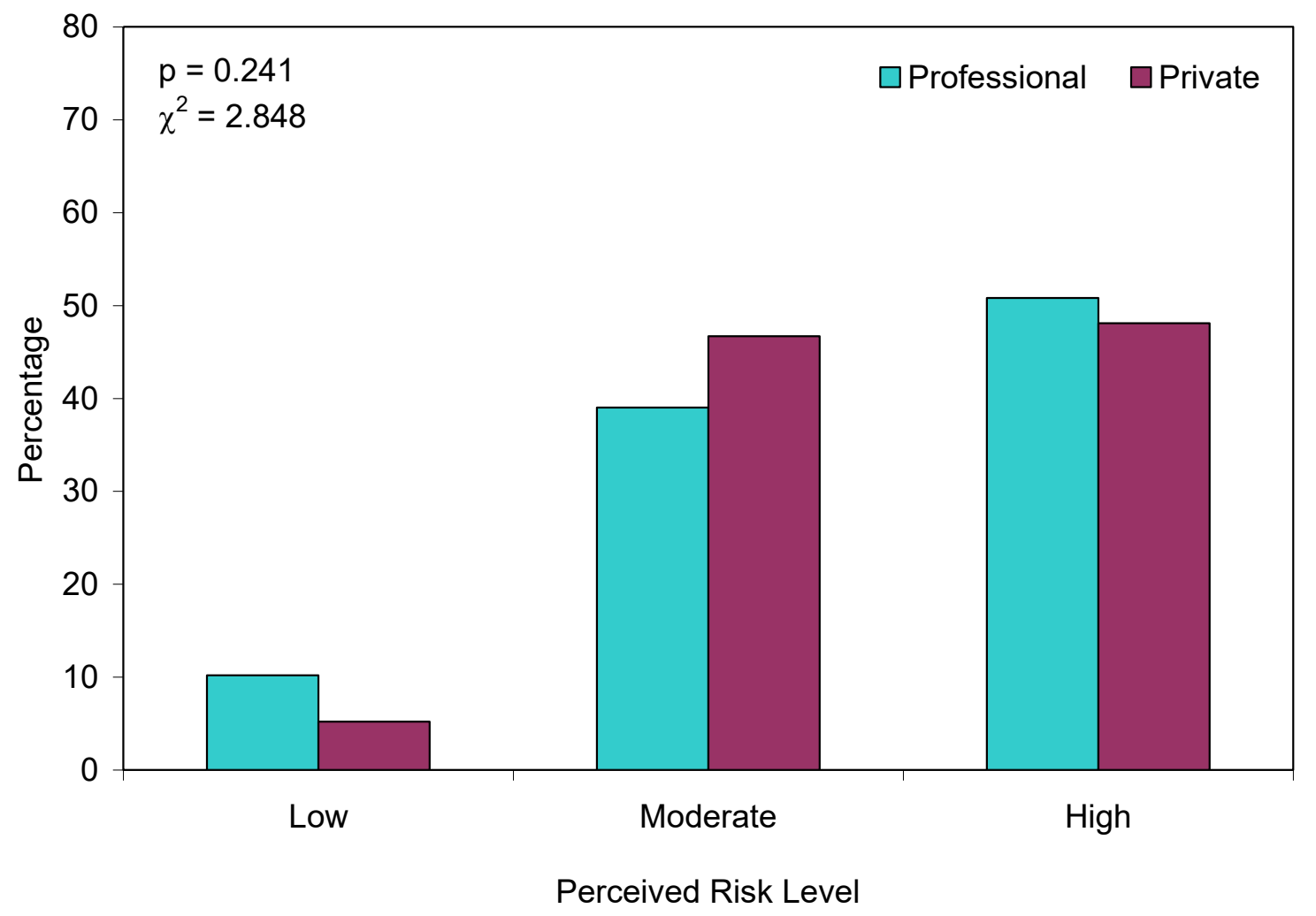

Figure 8. Risk perception distribution by driver license type 


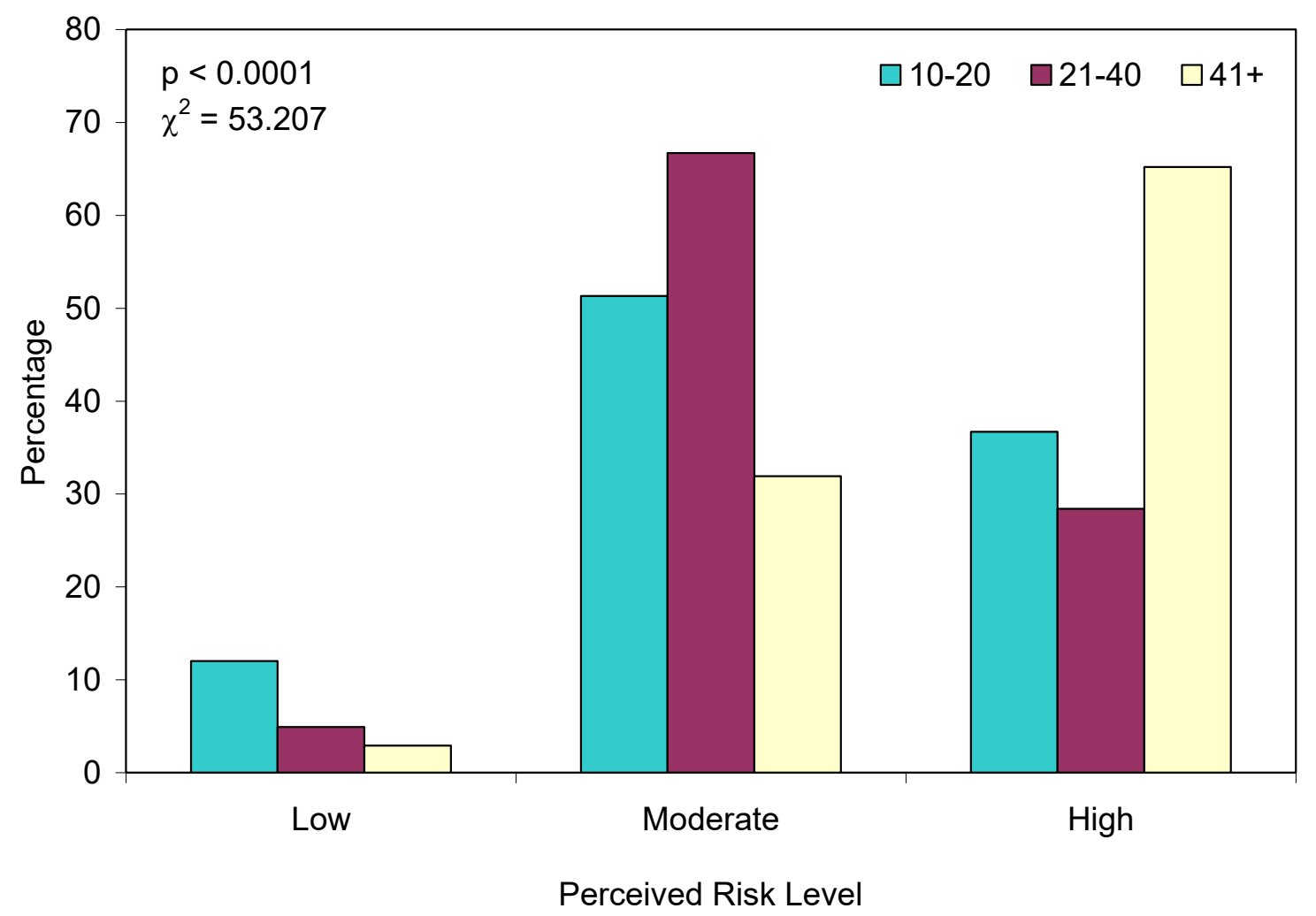

Figure 9. Risk perception distribution by driver daily traveled distance (kilometers) 


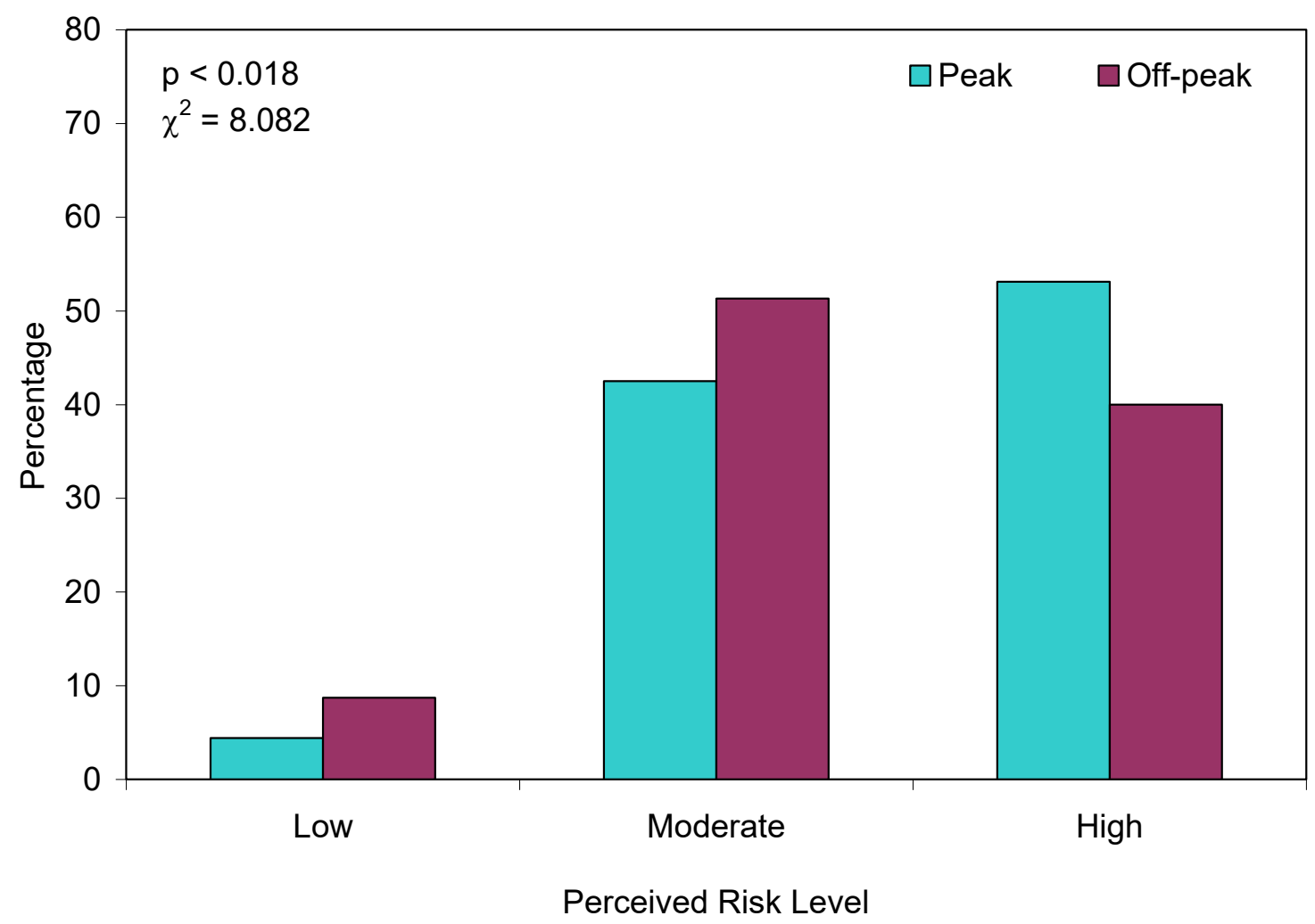

Figure 10. Risk perception distribution by driver time of driving 